Geopolítica(s) Revista de estudios sobre espacio y poder ISSN: 2172-3958

\title{
III Congreso Brasileño de Geografía Política, Geopolítica y Gestión del Territorio: enlaces, pluralidad y renovación de un campo ${ }^{1}$
}

\author{
Juliana Nunes Rodrigues ${ }^{2}$ y Licio Caetano do Rego Monteiro ${ }^{3}$
}

Recibido: 30 de septiembre de 2019 / Aceptado: 30 de octubre de 2019

Cómo citar: Nunes Rodrigues, Juliana \& Rego Monteiro, Licio Caetano do (2019) "III Congreso Brasileño de Geografía Política, Geopolítica y Gestión del Territorio: enlaces, pluralidad y renovación de un campo". Geopolítica(s). Revista de estudios sobre espacio y poder, vol. 10, núm. 2, 341347.

En la tercera edición del Congreso Brasileño de Geografía Política, Geopolítica y Gestión del Territorio se ha debatido sobre la ampliación de la temática teórica y metodológica existente en la agenda de la geografía política que se practica hoy en Brasil. Esta ampliación pasa también por diálogos interdisciplinares, diferentes áreas de actuación profesional y conexiones académicas nacionales e internacionales. Este texto tiene como objetivo explicar las interfases, la pluralidad y el proceso de renovación del campo, más allá de hacer un balance preliminar del evento, realizado entre los días 10 y 14 de septiembre de 2018, en la Universidad Fluminense, en Niteroi.

Espacios internacionales, malla político-administrativa y la geografía política de los gobiernos constituyeron temas clásicos de un campo que se dedica al estudio de las relaciones entre espacio y poder político. Históricamente la Geografía Política se asocia originalmente al proceso de formación de los Estados modernos — sus fronteras, diseño y formato constituyeron objetos clásicos de análisis de la disciplina (Machado, 1993; Costa, 1991; Castro, 2005). Se destacaron, también, las condiciones de la población, la capital, la nación y su territorio, la relación población/recursos o la posición geográfica - temas importantes en el ambiente político e intelectual de la época-, privilegiados no sólo por la Geografía Política, sino que estuvieron en el centro de la misma Geografia y de otras ciencias humanas y socia-

1 (Nota del editor) Esta es una nueva sección de la revista, donde se encontrarán noticias sobre actividades académicas que entren dentro de nuestro ámbito de trabajo. En esta ocasión recogemos un informe completo sobre el III Congreso Brasileño de Geografia Política, Geopolítica y Gestión del Territorio.

2 Departamento de Geografia, Universidade Federal Fluminense (Brasil).

E-mail: jnunesrodrigues@yahoo.com.br

3 Departamento de Departamento de Geografia e Políticas Públicas, Universidade Federal Fluminense, Angra dos Reis (Brasil).

E-mail: liciocaetano@id.uff.br 
les. En efecto, dichas temáticas estuvieron vinculadas al contexto de institucionalización académica de la disciplina, acompañando el proceso de consolidación de los Estados nacionales.

Las críticas orientadas al exceso de formalidad de una Geografía Política del Estado y a la fijeza temática y escalar - tomando la escala del territorio nacional como una escala privilegiada - acabaron, por su parte, por abrir un campo de discusiones extenso sobre los fenómenos vinculados a las diversas formas de ejercicio del poder, entendidas como relaciones históricas y sociales multidimensionales y, por lo tanto, no restringidas al aparato político-jurídico del Estado. Estas críticas se desarrollaron desde diversas fuentes y orígenes en los años 1980 y 1990: a) las nuevas geografías del poder traídas por autores francófonos como Lacoste (1976), Claval (1979) y Raffestin (1980), b) la Geopolítica crítica de los anglosajones, como Ó Tuathail \& Dalby (1998) y Agnew (1998), y c) también en el ámbito de las geografías ibéricas y latinoamericanas, especialmente en la geografia política brasileña.

Sin abandonar una disciplina que considera el Estado como actor político inevitable, la Geografía Política contemporánea se interesa, de forma reconocidamente plural y heterodoxa (Agnew, 2003; Rosière, 2017), por los modos en que los conflictos crean espacios y lugares (Flint, 2009). La agenda actual se amplia, entonces, para tener en cuenta pactos y conflictos político-territoriales muchas veces efimeros y fluidos, con configuraciones reticulares y caracterizados por procesos marcados por agenciamientos e interacciones que complejizan y redefinen los espacios de las políticas en la diversas escalas.

En efecto, no sólo se reconoce una variedad de tipos de actores y agentes políticos institucionales e institucionalizados, sino que también se amplía el trasfondo teórico-metodológico para el análisis de la dimensión espacial de la política engendrada por actores y agentes no institucionalizados, desde la escala global a diferentes microescalas. Se renuevan, en síntesis, las temáticas abarcadas por el campo, como también las posibilidades de plantearse cuestiones y problemas teóricos clásicos a partir de una nueva mirada.

Particularmente en Brasil, observamos una renovación que se da desde el balance crítico de la geopolítica de cuño nacionalista traída por diversos autores (Sodré, 1976; Andrade, 1989; Costa, 1991), pasando por la reafirmación de la dimensión política del espacio (Becker, 1988; Castro, 2005) y por la pluralidad de influencias teóricas que configuran el panorama actual reunido en el CONGEO, expresado en las dos obras colectivas ya publicadas del evento (Silva, 2016; Ruckert, Silva \& Silva, 2018).

Para comprender bien nuestro evento nos tenemos que remontar a mayo de 2013, cuando un grupo de investigadores y profesores brasileños de Geografía creó una red de intercambios institucionales y académicos vinculados al campo de la Geografía Política en el país, denominado Red Brasileña de Geografía Política, Geopolítica y Gestión de Territorio (REBRAGEO). Este grupo ha estado intentando fortalecer las colaboraciones nacionales e internacionales con la finalidad de ampliar las reflexiones y discusiones sobre la espacialidad de la política en sus diversas escalas y configuraciones. Desde el origen del grupo, se consolidó el deseo de realizar encuentros regulares (bianuales), como forma de fortalecer las conexiones de la investigación académica en esta área del conocimiento. El objetivo era 
concebir encuentros académicos que pudieran reflejar la pluralidad del campo, garantizar la participación colectiva en su construcción, evitándose la centralización y la dispersión en eventos temáticos sin continuidad. Este deseo tomó forma y se concretó ya en el año siguiente, en 2014, con la realización del I CONGEO en la Pontificia Universidad Católica de Río de Janeiro (PUC-RJ, 2014). Dado el éxito del I CONGEO y los vínculos afianzados entre los investigadores, la REBRAGEO se articuló también para la creación de un grupo de trabajo (GT) en la Asociación Nacional de Posgrado e Investigación en Geografía (ANPEGE), en 2017. Se dio otro paso, aproximándose a la Comisión de Geografía Política de la Unión Geográfica Internacional (UGI), que apoyó la realización del III CONGEO, en 2018.

La interacción entre Geografía Política, Geopolítica y Gestión de Territorio se mostró acertada por reunir perspectivas particulares de abordaje de la relación entre territorio y la acción política, que se encuentran cercanas, pero que mantienen relaciones particulares con diferentes áreas del conocimiento. La Geopolítica se extiende mucho más allá de la Geografía. En el ámbito académico, aparece en las Relaciones Internacionales, en la Ciencia Política y en la Historia, principalmente, pero su campo de interés se extiende fuera de la Academia, en los medios de comunicación, la diplomacia y las instituciones militares. La Gestión del Territorio también se hizo presente en la esfera de la planificación estatal, en las organizaciones gubernamentales, en las empresas, en las ONG y en los movimientos sociales. El territorio ha sido un nuevo concepto de referencia para pensar las políticas públicas, y ese giro territorial es bastante propicio a una mayor abertura hacia las contribuciones geográficas. Aunque la Geopolítica y la Gestión del Territorio no se encierren en el campo más general de la Geografía Política, colocarlos en interacción posibilita el perfeccionamiento y actualización de conceptos, enfoques, temas y metodologías, tanto de carácter más aplicado como teórico. La organización de encuentros regulares se concretó, así, a partir de la creciente demanda de interlocuciones en un campo en franca expansión en el país. De forma gráfica, un simple sondeo hecho en el directorio de grupos de investigación del CNPq mostró que, en 2018, eran 17 los grupos que presentaban como palabra clave el término "geografía política", 45 con el término "gestión de territorio " y 78 con el término "geopolítica".

El CONGEO se inició en 2014, con una primera edición realizada en la PUC$\mathrm{RJ}$, en la que se presentaron 155 trabajos, entre comunicaciones y pósteres. En esa primera edición, titulada "Racionalidades y prácticas en múltiples escalas", el encuentro privilegió el debate sobre nuevas organizaciones políticas, económicas, culturales y tecnológicas en la contemporaneidad del siglo XXI. En 2016, la segunda edición del evento fue realizada en Natal (UFRN), donde contó con un público y repercusión de similar importancia, con 130 trabajos presentados. En ese II CONGEO, titulado "La integración sudamericana y la inserción de las regiones periféricas" fueron abordadas, particularmente, las contradicciones relativas al proceso de integración sudamericana y de inserción de regiones periféricas, tanto en el sistema-mundo como en los contextos nacionales, particularmente el brasileño. Ambas ediciones resultaron en publicaciones de libros y de sus actas, que han contribuido a la proyección y consolidación de las investigaciones en el área, más allá de haber tenido como resultados indirectos el establecimiento de convenios y colaboraciones internacionales entre los investigadores participantes. 
Es importante destacar que la comisión organizadora del CONGEO se modificó cada bienio, con el fin de ampliar la propuesta y fomentar una mayor implicación de investigadores de diferentes universidades brasileñas. En la tercera edición del evento, tuvimos un total de veintiséis profesores-investigadores directamente involucrados en la organización, aparte de la comisión científica y la comisión de apoyo formada por cerca de sesenta alumnos de la UFF (Niteroi y Angra dos Reis), de la UERJ (Rio de Janeiro y São Gonçalo) y de la PUC-Rio. Resaltamos también que la tercera edición del evento agregó nuevos nombres a la comisión científica original, con el claro objetivo de aumentar la representatividad, por medio del balance de la distribución regional de los grupos de investigación en Geografía Política registrados en el CNPq. De esta forma, partimos de un conjunto de seis o siete estados brasileños representados en la comisión científica de los dos primeros congresos, respectivamente, hasta un total de trece estados representados en 2018. Alcanzamos así una mayor diversidad en la composición de la comisión, comprendiendo incluso diversas universidades localizadas fuera del país. Con ese mismo propósito de ampliar la participación de profesores-investigadores y las interlocuciones, también se creó una comisión científica extranjera, que contó con participantes de catorce países, cuyos representantes contribuirían a la divulgación y proyección internacional del evento.

A partir de la diversidad de temáticas y perspectivas de investigación abarcadas - que animan nuestra tensión creativa-, consolidamos algunos principios, tales como:

- promoción del refuerzo de las redes de conexión entre los investigadores de Geografía Política, Geopolítica y Gestión del Territorio existentes en el país, cuyas investigaciones se realizan, muchas veces, en forma aislada, en perjuicio de la calidad de los trabajos y de la mejora de la capacidad de gestión de los poderes públicos en Brasil;

- la proyección nacional e internacional de los trabajos e investigaciones realizados, en vistas al desarrollo de colaboraciones entre investigadores brasileños del área con investigadores e instituciones extranjeras;

- el estímulo al intercambio, la calidad y la producción académica (graduaciones, masters y doctorados) de estudiantes y profesionales diversos, y

- el establecimiento de un diálogo de la Geografía con las Relaciones Internacionales, el Derecho Ambiental, la Administración Pública, Ciencia Política, la Sociología y las demás ciencias afines estimulando investigaciones interdisciplinares y plurales desde el punto de vista teórico y metodológico.

El III Congreso Brasileño de Geografía Política, Geopolítica y Gestión de Territorio (III CONGEO) fue, por lo tanto, expresión de un proceso de renovación. Una multiplicidad de temas y posibilidades teórico-metodológicas ganaron visibilidad en forma y contenido de los diferentes trabajos presentados durante los cinco días de encuentro. Se propusieron a los participantes ocho ejes temáticos orientadores para la sumisión de trabajos, que fueron: 
1) Geografía Política y Geopolítica: de los enfoques clásicos a las renovaciones contemporáneas.

2) (Geo)políticas de Medio Ambiente, gestión de los recursos y sostenibilidad.

3) Localismos, regionalismos, nacionalismos y globalismo

4) Fronteras y límites en múltiples escalas

5) Las escalas de gestión de las políticas públicas territoriales.

6) Integración regional y nuevos espacios de la cooperación y del conflicto internacional.

7) Territorio, política, ciudadanía y democracia.

8) Geografía política y enseñanza: innovaciones temáticas, conceptuales y metodológicas.

Las temáticas privilegiadas fueron, por lo tanto, variadas y contemplaron debates sobre democracia, ciudadanía, corrupción, gobernanza, desigualdad social, seguridad, violencia, regionalismos y cuestiones regionales, dinámicas fronterizas, conflictos político-ambientales, aparte de acuerdos y conflictos diversos que abarcan la escala de lo local, lo nacional y lo global. Recuérdese que, además de los grupos de discusión, el evento tuvo actividades tales como mesas redondas, que contaron con la participación de invitados brasileños y extranjeros calificados, dos conferencias de participantes extranjeros - Heriberto Cairo (Universidad Complutense de Madrid) y Virginie Mamadouh (Universidad de Amsterdam) - además de la participación de trabajos en formato de pósteres, realización de talleres impartidos por el IBGE y la realización de tres trabajos de campo (uno en el centro de la ciudad de Río de Janeiro y otros dos en la Costa Verde).

Es de resaltar en relación a los eventos anteriores la formación de dos ejes temáticos nuevos:

- el eje 7, "Territorio, política, ciudadanía y democracia", que aglutinó y confirió encuadre a temas y objetos de estudio actuales como: relaciones entre espacios públicos y espacios políticos; políticas de la diferencia y territorio; los nuevos espacios, canales y arenas del debate público; manifestaciones políticas, activismos sociales y derecho a la ciudad; territorios alternativos y política; política del paisaje, patrimonio y cultura; participación, representación y geografia; geografía del voto y conexión electoral; Geografía y Derecho: espacialidades de las normas y excepciones, $\mathrm{y}$

- el eje 8, “ Geografía política y enseñanza: innovaciones temáticas, conceptuales y metodológicas ", que se formó a partir de una sensibilidad creciente, sentida en la agenda de la Geografía Política brasileña, en relación a temas vinculados a la enseñanza de la Geografía.

Debemos subrayar que la demanda para la estructuración de dos nuevos ejes se manifestó en el encuentro precedente, ocurrido en 2016, en Natal, cuando un número considerable de trabajos sobre tales cuestiones estuvo disperso entre los demás ejes propuestos. Desde el punto de vista temático, por lo tanto, el III 
CONGEO innovó en la propuesta de nuevos ejes para dar soporte a estas discusiones.

En esta tercera edición, propusimos la temática general "Crisis y Reinvención de los espacios de la Política", alineada con la coyuntura de crisis y reflexión sobre las posibilidades e impedimentos para la acción y decisión política en los contextos brasileño y mundial. Consideramos que nuestra responsabilidad y compromiso en relación al encuentro fueron mayores aún, frente a las inquietudes del presente, que requieren lucidez y un ejercicio constante de análisis. A pesar de la agitación y de de las pasiones del momento, creemos que el evento permitió dar a conocer contribuciones de la Geografía Política, de la Geopolítica y Gestión del Territorio importantes para el entendimiento de algunas de las dimensiones del contexto que vivimos en nuestro país, y también de fenómenos políticos que están más allá de las particularidades político-institucionales y territoriales brasileñas.

El encuentro tuvo un total de 527 trabajos, de los cuales 73 eran pósteres y 394 comunicaciones orales. Tuvimos 575 participantes inscritos, desde 24 unidades de la federación, aparte de los participantes extranjeros de 11 países. En total fueron 112 doctores, 140 másteres, 124 graduados y 198 estudiantes de pregrado. Entre graduados y másteres eran 204 alumnos de Máster y Doctorado, lo que indica la importancia del congreso en el recorrido formador de investigadores en el área.

Aparte de la publicación del cuaderno de Resúmenes y Actas del III CONGEO, el evento dio lugar a la publicación de un número especial de la Revista Brasileira de Geografia con los mejores trabajos presentados y del libro Crisis y Reinvención de los espacios de la Política (2019), organizado por Juliana Nunes y Licio Rego Monteiro, con los textos de los disertantes.

\section{Bibliografía}

Agnew, John (1998) Geopolitics: re-visioning the world politics. New York: Routledge.

Agnew, John (2003) "Contemporary Political Geography: Intellectual Heterodoxy and its Dilemmas". Political Geography, vol. 22, núm. 6, 603-606.

Andrade, Manuel Correia de (1989) Geopolitica do Brasil. São Paulo: Ática.

Becker, Bertha K (1988) "A geografia e o resgate da geopolítica”. Revista Brasileira de Geografia, vol. 50, número especial t. 2, 99-125.

Castro, Iná Elias de (2005) Geografia e política: território, escalas de ação e instituições. Rio de Janeiro: Bertrand Brasil.

Claval, Paul (1979) Espace et pouvoir. Paris: Presses Universitaires de France.

Costa, Wanderley Messias da (1991) Geografia política e geopolítica. São Paulo: Edusp.

Costa, Wanderley Messias da \& Théry, Hervé (2012) "Quatre-vingts ans de géopolitique au Brésil : de la géographie militaire à une pensée stratégique nationale”. Hérodote, núm. 146-147, 253-276.

Flint, Colin (2009) "Political Geography". En D. Gregory, R. J. Johnston, M. J. Watts y S. Whatmore (eds.) The Dictionnary of Human Geography. Oxford: Wiley-Blackwell, 549-551.

Lacoste, Yves (1988) [1976] A geografia - isso serve, em primeiro lugar, para fazer a guerra. Campinas: Papirus.

Machado, Lia O. (1993) "Geografia Política e Ciências Sociais: um comentario”. Anais do II Seminario Latinoamericano de Geografia Critica. Buenos Aires. 
Ó Tuathail, Geraóid \& Dalby, Simon (1998) Rethinking geopolitics. London: Routledge.

Ó Tuathail, Geraóid (1996) Critical geopolitics: the politics of writing global space. Minneapolis: University of Minnesota Press.

Raffestin, Claude (1993) [1980] Por uma geografia do poder. São Paulo: Ática.

Rosière, Stéphane (2017) “Dix ans de L’Espace politique. Géographie politique et géopolitique en question". L'Espace Politique, núm. 32. [En línea. URL: $<$ http://journals.openedition.org/espacepolitique/4327>. Consultado el 23 de octubre de 2019].

Ruckert, Aldomar; Silva, Augusto C. P. \& Silva, Gutemberg V. (orgs.) (2018) Geografia Política, Geopolítica e Gestão do Território: a integração sulamericana e a inserção das regiões periféricas. Porto Alegre: Letra 1.

Silva, Augusto C. P. (org.) (2016) Geografia Política, Geopolítica e Gestão do Território: racionalidades e práticas em múltiplas escalas. Rio de Janeiro: Gramma.

Sodré, Nelson Werneck (1976) Introdução à geografia. Petrópolis: Vozes. 